\title{
DIETARY PATTERN OF SOME EGYPTIAN UNIVERSITY YOUTH
}

\author{
Mohamed A.M.S. Saraya ${ }^{1 *}$, I. Soliman ${ }^{2}$ and Gehan A. El-Shorbagy ${ }^{1}$ \\ 1. Dept. Food Sci., Fac. Agric., Zagazig Univ., Egypt \\ 2. Dept. Agric. Econ., Fac. Agric., Zagazig Univ., Egypt
}

Received: 01/08/2021 ; Accepted: 25/08/2021

\begin{abstract}
This study was focused on the daily dietary pattern of university youth, where about $60 \%$ of Egyptians are within the youth age "18-40yrs". A purposive Cluster Two stages random sampling design was applied. Two universities located in Cairo were selected (The Future, a private university,) and (Ain Shams a governmental university). The respondent students were from the faculties of medicine, engineering, dentistry, and pharmacy. The Covid-19 epidemic that lasted for two years had limited the sample size and decreased the response rate of respondents to the questionnaire. The total sample size was 50 students within twenties 18 -24 years, 38 males, and 12 females. An online, validated, questionnaire "FFQ" was used. The questionnaire included 60 food items. It was adapted to fit the Egyptian society dietary traditions and taste. Due to the limitations of the sample size, the analysis was restricted to compare between male and female university youth. The daily dietary pattern was aggregated into three food subgroups (vegetal, animal and snacks). The share of each subgroup in major nutrients (Kcal, Protein, Fats, and Fe) was estimated. A Chi-square test for the independency of the two daily dietary pattern of male and female students was applied. Major result and conclusions showed that: The daily dietary Kcal intake of the male students looked healthier than the female students because of higher vegetal foods intake share. The female students snack diets share in daily Kcal intake was higher than the male students. It implies that the female students tend to have more candy, cookies chocolate and beverages. Probably, they think it is more elegant habits that fit them as girls, even though, these foods are costly and leading to exposure to obesity and diabetes, if lasted with age. The proportion of animal foods in gross protein intake was too high. The recommended animal protein share is $\leq 33 \%$ of the daily gross protein intake. Therefore, the body metabolizes excess protein as calories source and drains nitrogen in urine with burden on kidney functions, with age it would cause Gout disease and/or Kidney failure. Animal products are expensive because paying a high price for animal products is for essential amino acids not as a source of energy. There are plenty of much cheaper carbohydrate foods. The apparent higher share of animal products in fat content of the daily diet is not a healthy phenomenon. The high fats as saturated fatty acids in red meat and fast foods are harmful. If such dietary habit lasted with age with often increase in income, and naturally, less physical activity most probably would imply exposure individuals to obesity, heart diseases and arteriosclerosis. Such phenomenon stems from dietary customs of the university youth to have fast foods as burger, nuggets, fried chicken with french-fries is not only expensive, but it these meals are also much greasy from low quality imported frozen meat mixed with soybean and greasy spicy top dressings,. They are called in west "unhealthy Junk foods". However, the developing countries youth simulate the western diets as modern culture. Even though, the obesity rate in USA has doubled within the last three decades. Exposure to high blood level of bad cholesterol accelerate the probability of early arteriosclerosis. Even though, the $\mathrm{Fe}$ intake from animal foods is more utilizable than other food sources having frequent tea, coffee, gaseous water with or immediately after meals most probably destroys the diet $\mathrm{Fe}$ without utilization. Such types of beverages might cause gastritis which in turn decrease the potentiality of digestion and absorption of digested food.
\end{abstract}

Key words: Dietary patterns, Egyptian university, youth diet, male and female diet patterns.

\footnotetext{
* Corresponding author: Tel. :+201098460460

E-mail address: mohamedsaraya2021@gmail.com
} 


\section{INTRODUCTION}

Diet is a complex exposure variable, which calls for multiple approaches to examine the relationship between diet and healthy life performance, either physically, mentally or disease risk. Unfortunately, compensation of dietary deficiency at childhood stage, most probably, would not be effective at older ages, even though if food accessibility were available (Soliman and Eid, 1995a).

Dietary guidelines for the promotion of overall good health and the prevention of disease often play an important role in setting nutritional policy and in the education of the public about healthy food choices. Adequate healthy diet is essential component in human development. Although much has been written about adherence to such guidelines, until recently there was no evidence on whether adherence to specific dietary guidelines is associated with better health (Soliman, 1998).

Western nations have seen a decline in diet quality over the past decades; total calories, added sugars, refined carbohydrates, fats and meat consumption have increased substantially. The food and drink we consume; our activity levels and our weight all influence the magnitude of risk along our lifespan. The risk expands from probable sickness up to premature death. Nutrition education promotes our nutrition awareness towards how our daily lifestyle should be based upon an equilibrium between healthy dietary pattern, suitable physical activity and keeping our weight close to optimum to reduce diversified types of risk (Varela-Moreira et al., 2010; Cordoba-Caro et al., 2012). These changes have coincided with a same trend cited recently by Cutillas-Torin $\boldsymbol{e t}$ al. (2015). Contradictorily, the traditional Mediterranean diets have been shown to confer multiple health benefits (Estruch et al., 2013; Sofi et al., 2014; Pimento et al., 2015).

The assessment of nutrition status of any community or society, is classified into two approaches. These are dietary pattern and dietary adequacy, (Soliman, 2000). This study focused on the daily dietary pattern. The Egyptian population is specified, currently a youth population, where about $60 \%$ of
Egyptians are within the youth age "18-40yrs" (CAPMS, 2020) Therefore, the target group in this study was the university youth. The impact of gender type, on the dietary pattern were assessed.

\section{MATERIALS AND METHODS}

\section{Data Base}

A purposive Cluster (Area) two stages sampling design was applied (Soliman, 2021). Two universities located in Cairo were selected (The Future and Ain Shams University). The first one is a private university which represented a community of high standard of living as the tuition fees are quite high. The second represented a governmental university of quite low tuition fees, which supposed to admit the students from medium to low-income households. The respondent students were from the faculty of medicine, engineering, dentistry, and pharmacy. It should be mentioned that the Covid-19 epidemic, lasted for two years with a decrease in the response rate of respondents to the questionnaire, had limited the sample size. The total sample size was 50 students 38 males and 12 females within twenties of age (18 -24 years old).

\section{Methodology}

The study applied an online, validated, questionnaire "FFQ" (WHO, 2013). The questionnaire included 60 food items. However, it was adapted to for the Egyptian society and taste (El-Asfahani et al., 1989). Because of relatively small sample size due to the limitations mentioned above, the prudent daily dietary pattern was modified from the standard form. Three food subgroups were aggregated (Vegetal food items, Animal food items, and snacks). The share of each subgroup in major macronutrients and micronutrients were estimated for male students and female students. These nutrients were daily intake of Energy (Kcal), Protein, Fats, and Iron (Fe). Also due to the limitations of the sample size, the analysis was restricted to compare between the dietary pattern of male and female university youth. It should be mentioned that the food group of snacks was a term used in this study as a workable definition of fast-food meals, nuts, 
sweets, cookies, candy, chocolates and beverages that were eaten either in or out of the house or purchased as a takeaway.

Dietary pattern analysis seeks to understand how people are eating. Traditionally, nutrition research has focused on whether individual nutrients and foods are linked with health outcomes or diseases. Investigating nutrition using this approach has a few limitations. People do not eat individual nutrients and foods in isolation. People eat meals and snacks which contain a variety of ingredients that interact. The frequency of eating food items and the share in providing utilizable nutrients, either the macronutrients or micronutrients is the dietary pattern concepts adapted in this study (Soliman, 2008). A Chi-square test for the independency of the two daily dietary pattern of male and female students was applied. The null hypothesis was that the two gender dietary patterns are independent with df. (2-1) (3-1) = 3, (Myers et al., 2010).

\section{RESULTS AND DISCUSSION}

\section{Daily Dietary Pattern of University Youth}

Tables 1, 2, 3 and 4 and Figs. 1, 2, 3, 4, 5, 6, 7 and 8 present the average share as percentage of daily per capita consumption of Kcal, Protein, Fats, and $\mathrm{Fe}$ of consumed food items from the three mention food groups (vegetal, animal and snacks) for both male and female university students. As the application of $\chi^{2}$ test showed insignificant value of estimated $\chi^{2}$ for all daily dietary patterns (Tables 1, 2, 3 and 4), the male and female dietary patterns are independent, i.e., they were affected by diversified socioeconomic factors. However, the impacts of such factors on the dietary pattern would be investigated in another successive paper by standard of living (private versus public university) and by education program (medicine versus non medicine programs).

\section{Daily Dietary Calories Pattern}

Investigation of the two genders patterns, Table 1 and Figs. 1 and 2 showed that while the vegetal food items share in the university male student's daily Kcal-intake was higher than female's Kcal-intake, i.e., $56 \%$ and $51 \%$, respectively, the share of animal foods in female student daily dietary intake in daily Kcal intake for a female student was higher than the male student i.e., around $21 \%$ and $19 \%$, respectively. Snacks share in the daily dietary of the female's Kcal-intake was, apparently, higher than the male i.e., around $28 \%$ and $25 \%$, respectively. The estimated weighed average of the sample showed that: About 55\%, 20\% and 26\% of the $\mathrm{Kcal}$ in the daily dietary pattern of the university youth were from vegetal foods, animal product foods and snacks food items, respectively.

Therefrom, the daily dietary Kcal intake of the male students looked healthier than the female students because of higher vegetal foods intake share. The female students snack diets share in daily Kcal intake was higher than the male students. It implies that the female students tend to have more candy, cookies chocolate, sweets, and beverages. Probably, they think it is more elegant habits that fit them as girls, even though, these foods are costly and leading to exposure to obesity and diabetes, if lasted with age.

\section{Daily Dietary Protein Pattern}

From Table 2 and Figs. 3 and 4, there are noticed apparent difference between male and female dietary pattern of protein from snacks daily intake i.e., around $19 \%$ and $21 \%$, respectively. The animal diets share in daily consumed gross protein approached $47 \%$ for a male students and $48.3 \%$ for a female students, while the vegetal protein share diet was $34 \%$ and $30 \%$ in male and female diet, respectively. The sample weighted average showed that about $33 \%, 47 \%$ and $19 \%$ of the protein of the daily dietary pattern of the university youth were from vegetal foods, animal product foods, and snack food items, respectively.

The proportion of animal products protein in gross protein was too high, although the age of most sampled students were above 20 years old. Health-wise and economic-wise it was not a recommended phenomenon. The recommended animal protein share should not exceed $33 \%$ of the daily per capita gross protein consumed, (Soliman and Eid, 1995b). Otherwise, the body metabolizes excess protein as a source of calories and drains nitrogen in urine with burden on kidney function. Continuation of this pattern with age would cause Gout disease and/or 
Table 1. Daily dietary calories pattern of university youth (Kcal)

\begin{tabular}{lcccc}
\hline & Attribute & \multicolumn{2}{c}{ Gender } & Total \\
\hline Variable & Estimate & Male & Female & \\
\hline Vegetal Foods & $\boldsymbol{\%}$ & 56.1 & 50.7 & $\% 54.8$ \\
& SE & \pm 9.1 & \pm 8.1 & \\
Animal Foods & $\mathbf{\%}$ & 19.2 & 20.9 & $\% 19.61$ \\
Snacks \& Beverages & SE & \pm 7.9 & \pm 6.7 & \\
Sample Size & $\mathbf{\%}$ & 24.7 & 28.4 & $\% 25.59$ \\
Chi Square & S.E. & \pm 6.6 & \pm 6.3 & \\
\hline
\end{tabular}

Compiled and calculated from the Sample Survey Data

$\mathrm{ns}=$ not significant, $*$ = significant at Prob. 90\%, Significant at Prob. 95\%

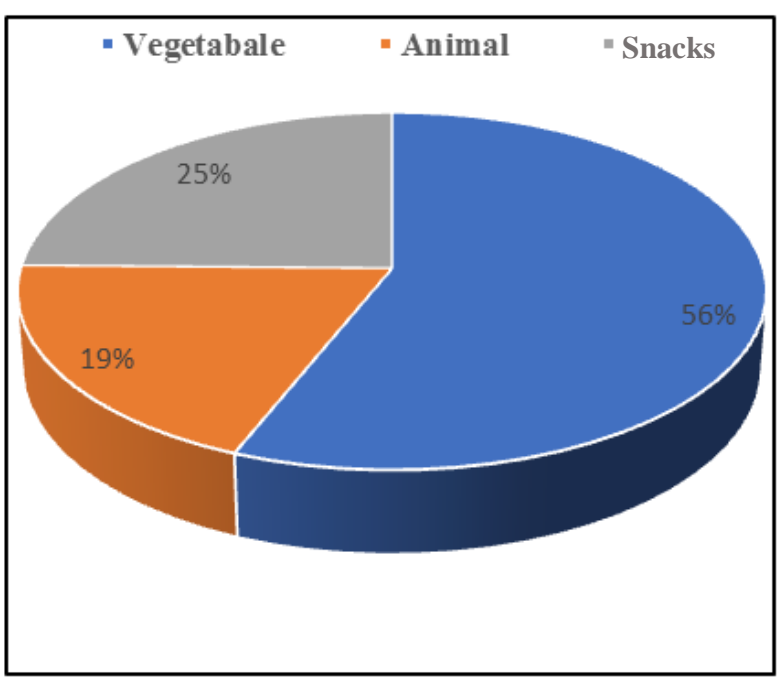

Fig. 1. Daily Kcal intake by university male students

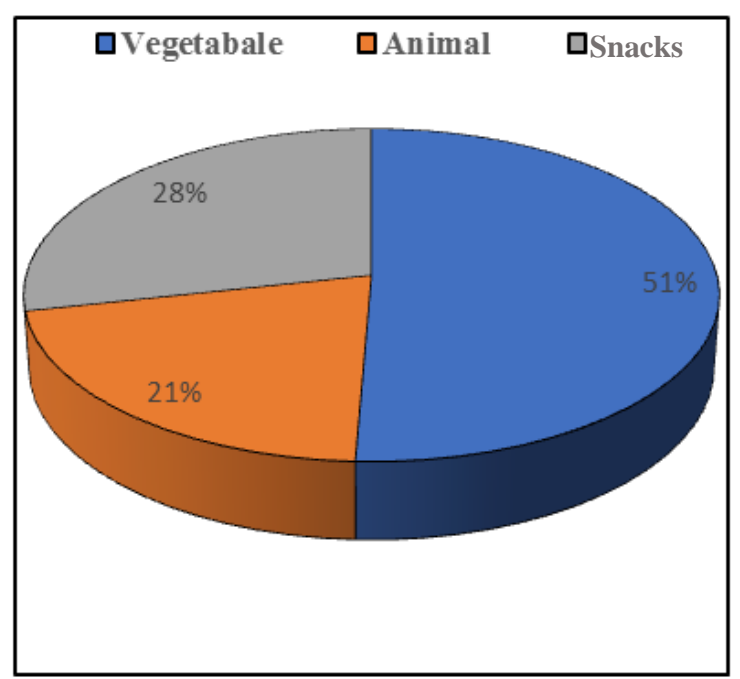

Fig. 2. Daily Kcal intake by university female students

Table. 2 Daily Dietary protein pattern of university students

\begin{tabular}{lcccc}
\hline & Attribute & \multicolumn{3}{c}{ Gender } \\
\hline Variable & Estimate & Male & Female & Total \\
\hline Vegetal Foods & \% & 34.1 & 30.4 & 33.2 \\
& S.E. & \pm 9.2 & \pm 8 & \\
Animal Foods & $\mathbf{\%}$ & 47.1 & 48.3 & 47.4 \\
& S.E. & \pm 11.3 & \pm 9.6 & \\
Snacks \& Beverages & $\mathbf{\%}$ & 18.8 & 21.3 & 19.4 \\
Sample Size & S.E. & \pm 6.7 & \pm 5.8 & 50 \\
Chi Square & $\mathbf{N}$ & 38 & 12 & $\mathrm{df}=2$ \\
Chi Square & $\boldsymbol{\chi}^{2}$ & & 0.356 & $\mathrm{df}=2$ \\
\hline
\end{tabular}

Compiled and calculated from the Sample Survey Data

ns $=$ not significant, $*$ = significant at Prob. 90\%, Significant at Prob. 95\%. 


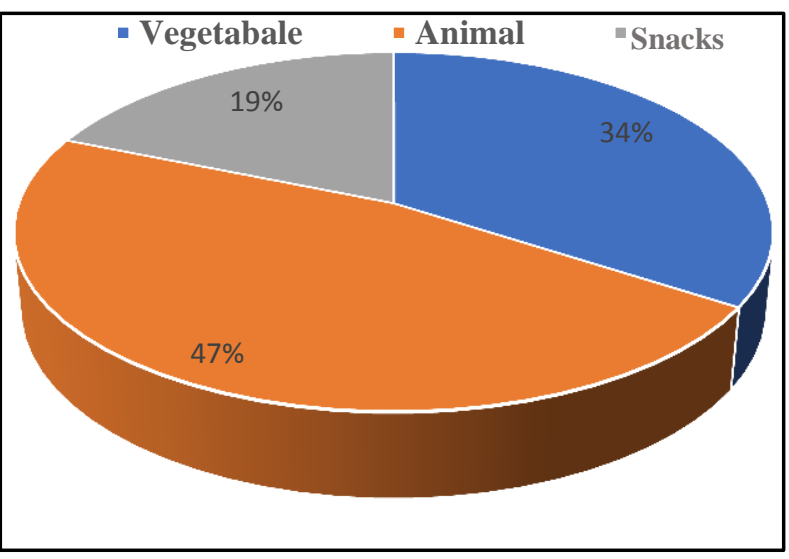

Fig. 3. Daily protein intake by university male students

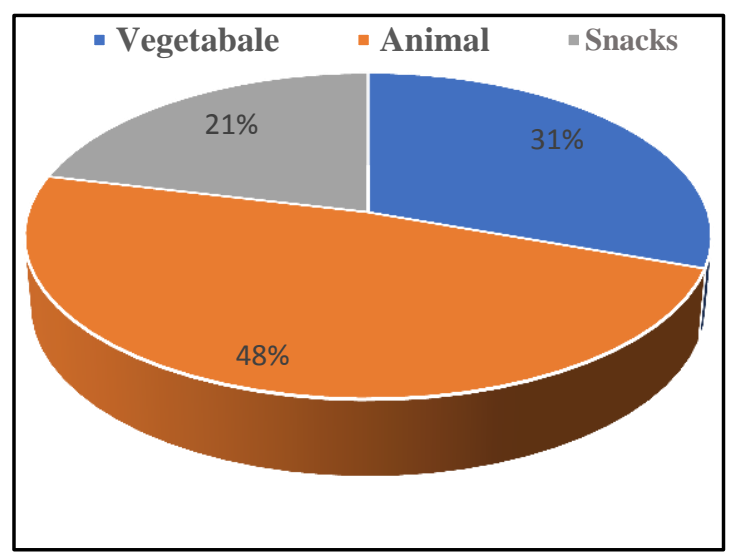

Fig. 4. Daily protein intake by university female students

Table 3. Daily dietary fat pattern of university students

\begin{tabular}{|c|c|c|c|c|}
\hline \multicolumn{2}{|l|}{ Attribute } & \multicolumn{2}{|c|}{ Gender } & \multirow{2}{*}{ Total } \\
\hline Variable & Estimate & Male & Female & \\
\hline \multirow{2}{*}{ Vegetal Foods } & $\%$ & 35.3 & 36.1 & \multirow{2}{*}{35.5} \\
\hline & SE & \pm 10.2 & \pm 8.2 & \\
\hline \multirow{2}{*}{ Animal Foods } & $\%$ & 41.2 & 36.6 & \multirow{2}{*}{40.1} \\
\hline & SE & \pm 13.1 & \pm 9.3 & \\
\hline \multirow{2}{*}{ Snacks \& Beverages } & $\%$ & 23.5 & 27.3 & \multirow{2}{*}{24.4} \\
\hline & SE & \pm 8 & \pm 7.5 & \\
\hline Sample Size & $\mathbf{N}$ & 38 & 12 & 50 \\
\hline Chi Square & $\chi^{2}$ & \multicolumn{2}{|c|}{0.232} & $\mathrm{df}=2$ \\
\hline
\end{tabular}

$\mathrm{SE}=$ Standard error.

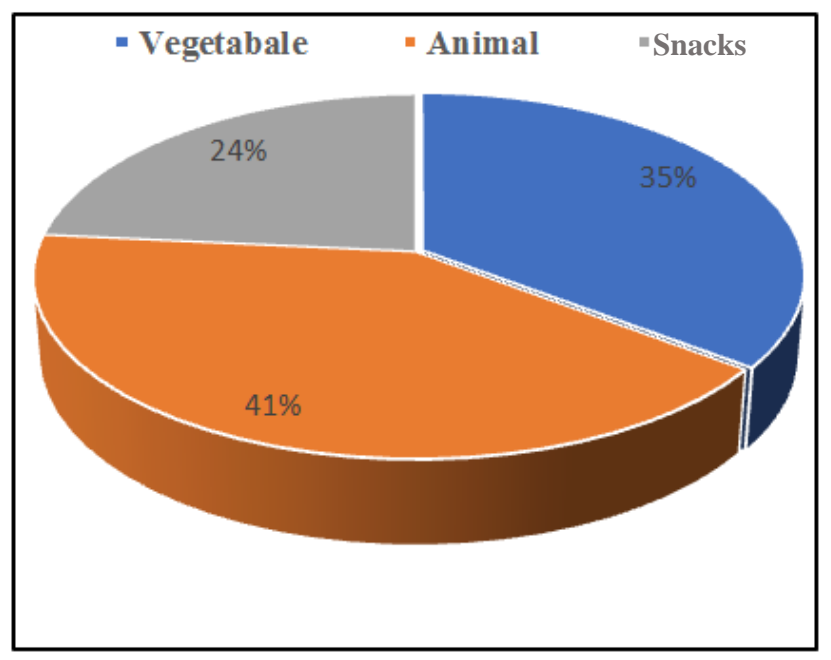

Fig. 5. Daily fat intake by university male students

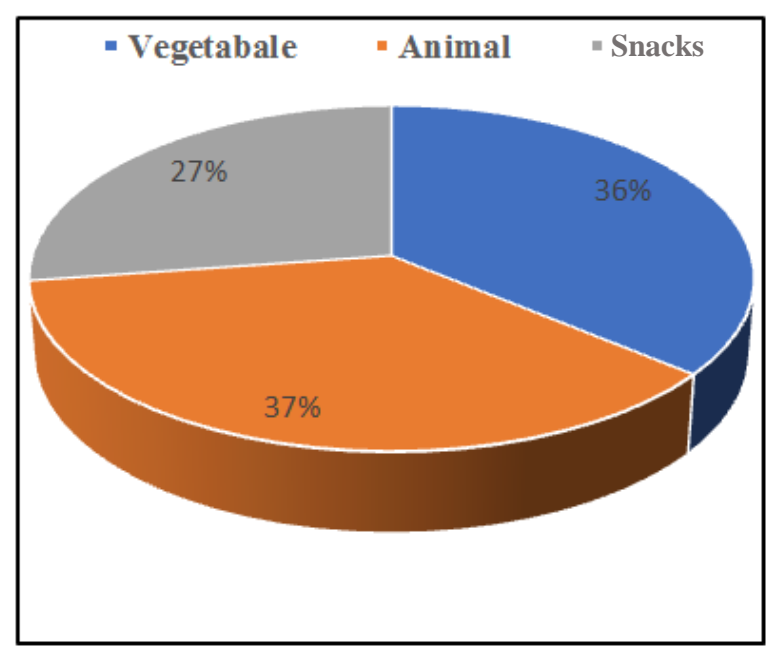

Fig. 6. Daily fat intake by university female students 
Table 4. Daily dietary Fe. pattern of university students

\begin{tabular}{llccc}
\hline \multicolumn{1}{c}{ Attribute } & & \multicolumn{2}{c}{ Gender } & \multirow{2}{*}{ Total } \\
\cline { 1 - 4 } Variable & Estimate & Male & Female & \\
\hline \multirow{2}{*}{ Vegetal Foods } & $\mathbf{\%}$ & 58.6 & 54.2 & \multirow{2}{*}{57.54} \\
& $\mathbf{S E}$ & \pm 10.7 & \pm 7.20 & \\
Snimal Foods & $\boldsymbol{\%}$ & 20.5 & 21.9 & 20.84 \\
& $\mathbf{S E}$ & \pm 10.3 & \pm 7.30 & \\
Sample Size & $\boldsymbol{\%}$ & 20.9 & 23.9 & 21.62 \\
Chi Square & $\mathbf{S E}$ & \pm 5.5 & \pm 4.6 & 50 \\
\hline
\end{tabular}

$\mathrm{SE}=$ Standard error.

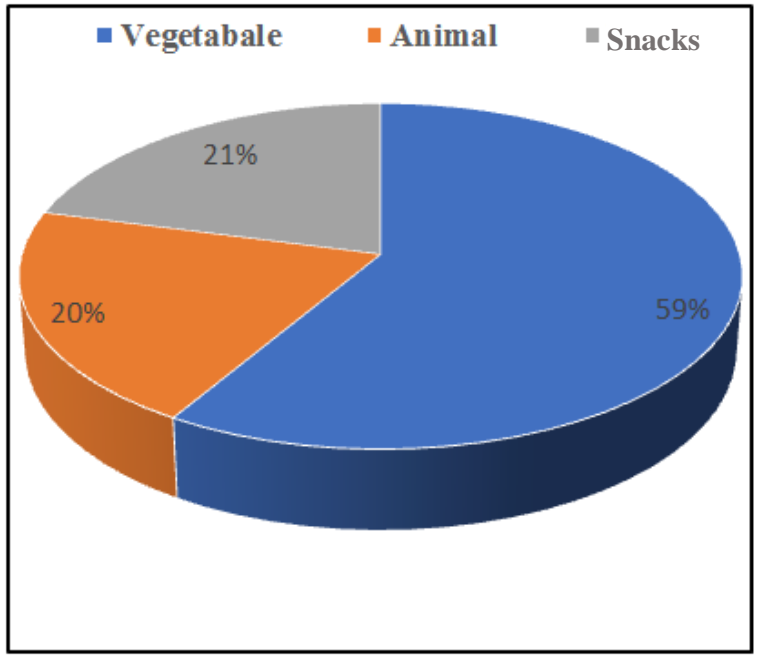

Fig. 7. Daily Fe intake by university male students

kidney failure. Animal products protein is expensive as the consumer pays high price for animal protein for its essential amnio acids not as a source of energy, because there are plenty of carbohydrate foods are much cheaper as energy sources.

\section{Daily Dietary Fat Pattern}

From Table 3 and Figs. 5 and 6, the vegetal foods share in the daily fat content for the female students were slightly higher than the male i.e., $36 \%$ and $35 \%$, respectively. However, the daily dietary pattern of the two genders was distinct with respect to the two other food

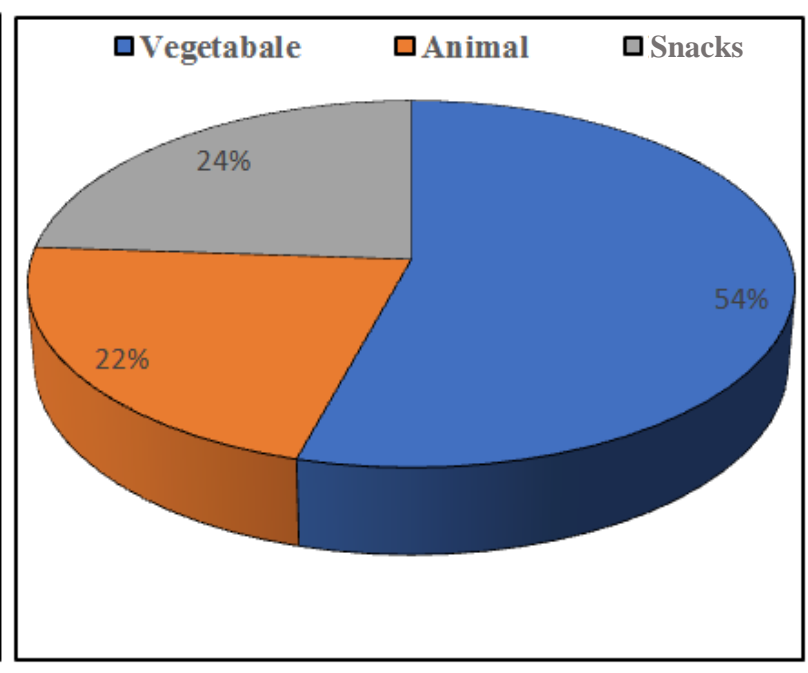

Fig. 8. Daily Fe intake by university female students

groups, animal foods and snacks. While the male students showed a relatively higher share of animal foods in fat content, i.e., about $41 \%$ of the total daily diet fat content, the animal foods share in the daily diet fat content for the female student was $36.6 \%$. The snacks showed a reverse dietary pattern. It showed a relatively higher share of such food group in the daily diet fat content for the female students reaching about $27 \%$, comparing with $24 \%$ fats share from the male students daily dietary intake. The sample weighed average showed that about $35 \%, 40 \%$ and $25 \%$ of fats content of the daily dietary pattern of the university youth were from 
vegetal foods, animal products and snacks food items, respectively.

The apparent higher share of animal foods in the fat content of the daily diet is not a healthy phenomenon. The red meat plates and fast foods are a main source of greasy foods. Their fats are saturated fatty acids type. If such dietary habit lasted with age, associated, usually, with higher income and less physical activity, it would most probably expose consumers to obesity, heart diseases and arteriosclerosis. Such phenomenon stems from the dietary customs of the youth to have takeaway and fast foods such as burger, nuggets, fried chicken and french-fries. Such meals are not only expensive, but they are also greasy foods prepared from low quality imported frozen meat mixed with soybean and spicy greasy on top dressings, (Soliman, 2021). Such meals are called in west "Junk foods" because they are unhealthy. However, the developing countries youth simulate the western dietary pattern of the developed countries, assuming they simulate a better cultural. Even though the obesity rate in USA has doubled within the last three decades. Animal fats compose of saturated fatty acids that are a major factor towards obesity and exposure to high concentration of bad cholesterol in blood, that accelerates the probability of early arteriosclerosis. In addition, numerous fast-food stores intend to fry the fast-food meals with cheap low-quality oils, to enlarge their market revenue share. These probable negative impacts would be enlarged with Current wide expansion in fast food stores because of the high profit, with poor food surveillance and inflationary-economic recession during COVID-19-pandemic" era.

\section{Daily Dietary Iron Pattern}

Table 4 and Figs. 7 and 8, showed that the vegetal foods in the males' daily diet provided around $58.6 \%$ of the daily $\mathrm{Fe}$ content i.e., apparently higher than the females' students (54\%). Both genders daily diet from animal foods provided around $21 \%$ and $22 \%$ of the daily diet Fe content. However, female students get more $\mathrm{Fe}$ than males from snacks, i.e., $24 \%$ $21 \%$ of $\mathrm{Fe}$ content, respectively. The weighed sample average showed that about $57.5 \%, 21 \%$, and $22 \%$ of the daily diet were from vegetal foods, animal foods and snacks.
Even though, the $\mathrm{Fe}$ intake from animal foods is more useful and utilizable than other food sources having frequent tea, coffee, gaseous water with or immediately after meals most probably destroys the diet Fe without any utilization. In addition, such types of beverages might cause gastritis which in turn decrease the potentiality of digestion and absorption of digested food.

\section{REFERENCES}

CAPMS (2020). Statistical Yearbook of Egypt, Published by Central Agency for Public Mobilization and Statistics, Nasr City, Cairo, Egypt.

Cordoba-Caro LG., L.M. Luego Perez and V. Garcia Preciado (2012). Nutrition adequacy students of compulsory $2^{\text {nd }} E d$. in Badajoz Nutr. Hosp., 27 : 1065-1971.

Cutillas-Tolin, A., L. Minguez-Alarcon, J. Mendiola, J.J. Lopez-Espin, N. Jørgensen, E.M. Navarrete-Munoz, A.M. Torres-Cantero and J.E. Chavarro (2015) "Mediterranean and western dietary patterns are related to markers of testicular function among healthy men, Human Reprod., 30 (12):2945 -2955.

El-Asfahani A., I. Soliman and W. Moussa (1989). Dietary Adequacy of University Students: A comparison between an Agricultural Society and an Oil Export Society. Int. Nutr. Bulletin, Geron-X Publisher, 40 (3): 535-541.

Estruch, J., E. Ros and M.A. Martinez-Gonzales (2013). Mediterranean diet for primary prevention of cardiovascular disease. $\mathrm{N}$. Engl. J. Med., 369: 676-677.

Myers J.I., A.D. Well and F.L. Jr. Robert (2010) Research Design and Statistical analysis, $3^{\text {rd }}$ Edition, Published by Routledge, New York, USA.

Pimento, A.M., E. Toledo, M.C. Rodrigues-Diez, A. Gea, R. Lopez-Iracheta, N. Shivappa, J.R. Hebert and M.A. Martinez-Gonzales (2015). Dietary indexes, food pattern and incidence of metabolic syndrome in Mediterranean Cohort: The SUN project. Clin, Nutr., 34: 508- 5014. 
Sofi, F., C. Macch, R. Abbate, G.F. Gensini and A. Cassini (2014). Mediterranean diet and health status: an updated meta-analysis and a proposal for literature-based adherence score. Public Health Nutr., 17: 2769-2782.

Soliman (2008). Approaches to improve healthy food patterns and family food security "regional workshop on how to raise awareness towards negative impacts of unhealthy food patterns on the health of youth and children" Organized by Education, Sci. and Culture Islamic Organization, Cairo, (December 23-25)

Soliman, I. (1998). Enriching Subsidized Wheat Flower for Bready Bockarie's with Fe". A Technical Report Provided to the Minister of Trade and Supply from his Advisory Committee, Cairo, Egypt.

Soliman, I. (2000). Food Nutrition and Development, Regional Training Course in Nutrition, Module 1, WHO Collaborating Cent. Res. Training in Nutr., Nat. Inst., Cairo, Egypt, P. 1 - 32.
Soliman, I. (2021). Principals of Sampling Surveys Design: Theory and Applications. Dar Al Fikr Al Arabi Press, Under Publication, Nasr City, Egypt.

Soliman, I. and N. Eid (1995a). Impacts of Egyptian Socio-Economic environment on dietary pattern and adequacy, Egypt. J. Agric. Econ., 5 (2): 757-782.

Soliman, I. and N. Eid (1995b). Animal protein food consumption pattern and consumer behavior. Egypt. J. Agric. Econ., 5 (2): 816783.

Varela-Moreira, G., J.M. Avila, C. Cuadrado, S. Del Pozo, E. Ruiz and O. Moreiras (2010). Evaluation of food consumption and dietary patterns in Spain by the food consumption survey: updated information. Eur. J. Clin. Nutr., 64 (Suppl 3) : S37-S43.

WHO (2013). Child growth, 2006 and 2007" (https://www.who.int\%20child\%20grow). 


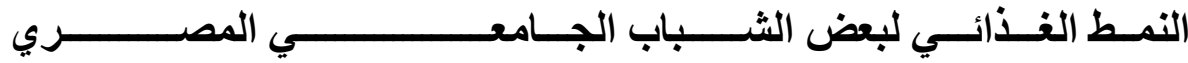

$$
\begin{aligned}
& \text { محمد أحمد مصيلحي سلامة سرايا1_- إبراهيم سليمان²- جيهان عبدالله الثوربجي1 } 1
\end{aligned}
$$

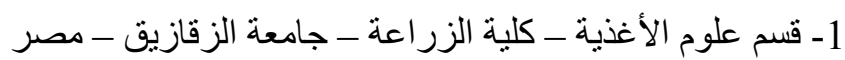

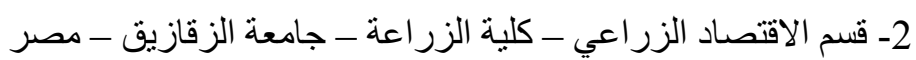

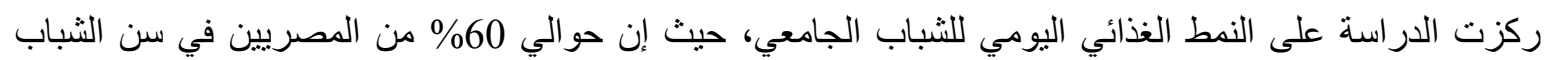

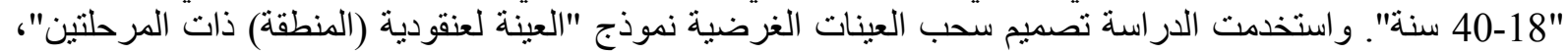

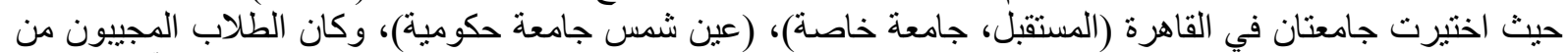

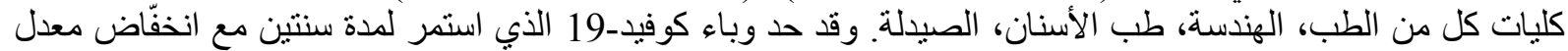

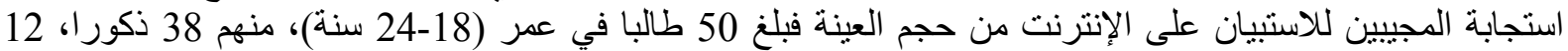

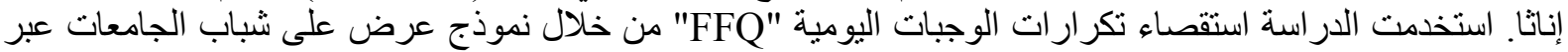

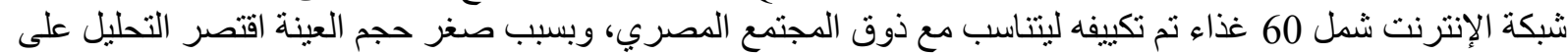

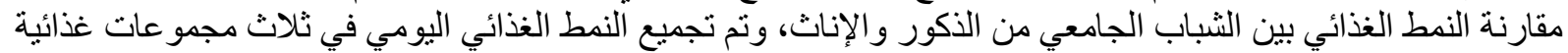

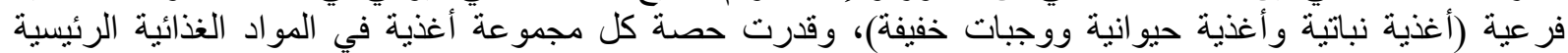

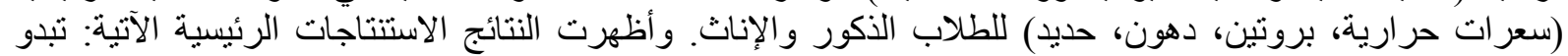

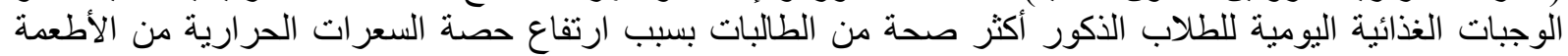

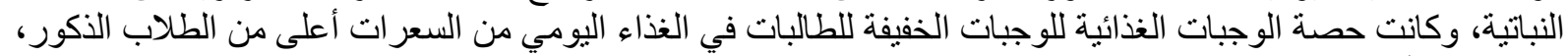

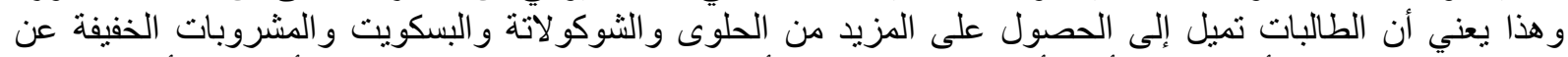

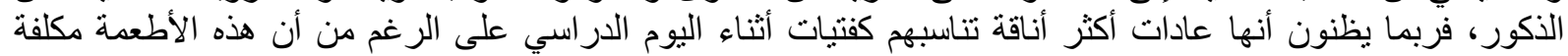

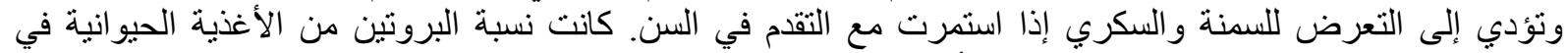

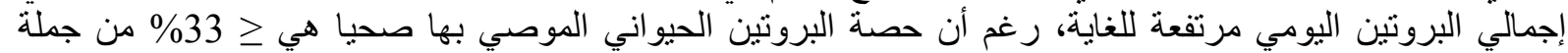

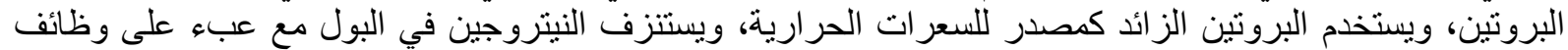

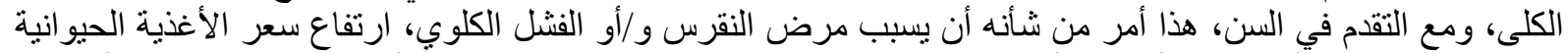

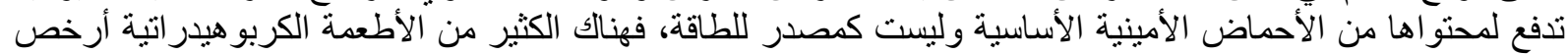

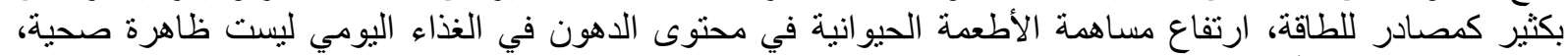

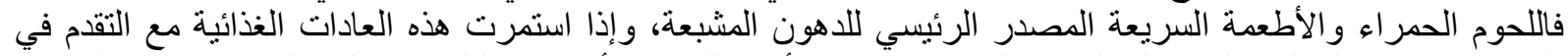

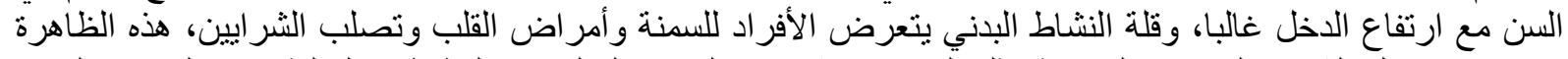

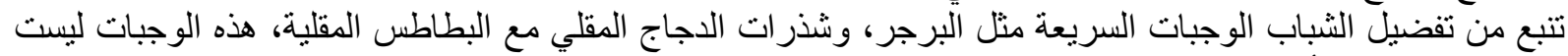

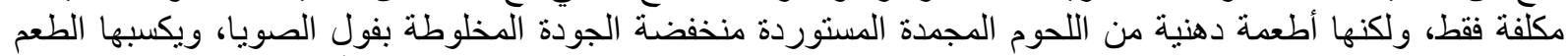

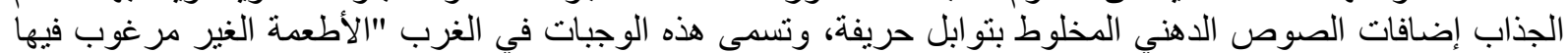

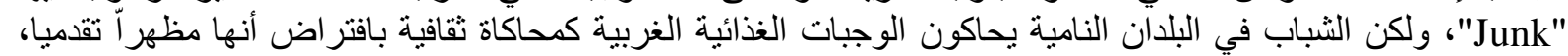

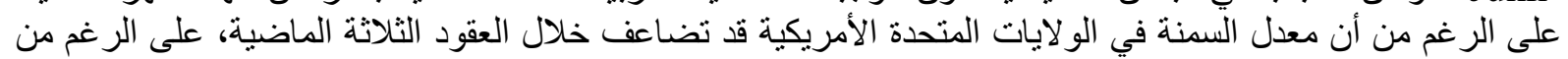

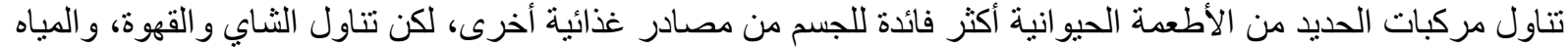

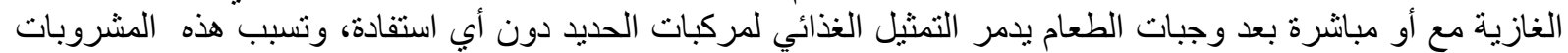

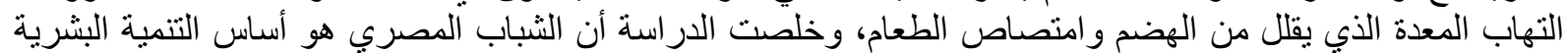

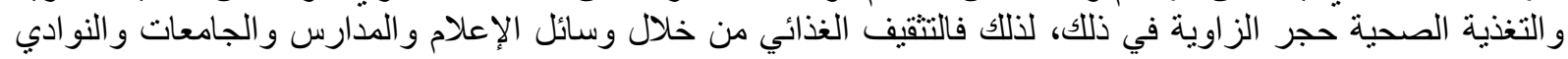
الرياضية والمنظمات غير الحكومية ضروري في البناء الوري في الغذّائي. 